\title{
REIs: Renewable Energy Infrastructures v1.0
}

\author{
C. Ford \\ College of Architecture, University of Nebraska-Lincoln, USA
}

\begin{abstract}
If we recognize that architects have historically played a role as technological innovators, then we must also recognize that architects, like scientists, are engaged in a form of applied research. Our university-based team has applied design thinking skills to a problem that involves energy production, energy transmission, and urban living. We believe a Renewable Energy Infrastructure (REI) will solve this problem.

A REI generates renewable energy megawatts (MW) at an industrial scale through the simultaneous harnessing of wind, solar, and geothermal resources, but within an integrated, holistic, and free-standing facility positioned in an urban environment. A REI is not a retrofit of a pre-existing architectural condition, but rather is conceived as a new typology to be owned and operated by an electrical utility. While current renewable energy technologies of industrial scale are typically located in rural areas, their greatest possible service to urban areas is limited due to measurable degradation rates along transmission lines and loss during step-downs at transformers.

The anticipated impact of this REI effort is the strategic formation of a cross disciplinary, design-led research team that delivers a technically-plausible, costeffective option for reducing greenhouse gas emissions from public power districts. Through the agency of a REI in our urban fabric, we improve the efficiencies of existing electrical technologies, improve urban land use policy, and provide an ecologically-responsible alternative that can dovetail with, or ultimately succeed, prevailing methods of electrical production at industrial scales. We are finding our preliminary REI design (v1.0) from March 2009 to have the technological potential of generating $124 \mathrm{MW}$ of renewable energy. Keywords: renewable energy, infrastructure, industrial-scale electrical energy production, urban land use policy, carbon emissions reduction, architect as technological innovator.
\end{abstract}




\section{The architect as Technological Innovator}

Despite recent scholarship and interest in interdisciplinary operations, much of our intellectual world still champions knowledge bases and fields of expertise that clearly originate from, and reside within, the centres of distinct disciplinary realms. While this tendency necessarily protects a discipline's true operational boundaries (for instance, in both the licensure and governance of professionals engaged in issues of life-safety), it also fosters an intellectual environment in which its knowledge base is characterized by re-productive thinking. In turn, these boundaries adversely discriminate against new creative discoveries from being made by outside individuals who exhibit productive thinking in the conceptualization of unprecedented solutions. For instance, consider the wide ranging differences between art, design and science while also recalling the types of individuals who have contributed to two or more of these realms.

Artists are primarily dependent upon creative thinking in order to solve aesthetic problems of their own making. Because both the conception and execution of an artist's work remains subjective, the artistic problem framed is as negotiable as the solution(s) itself. Furthermore, because the artist concerns himself with solutions that shall exist in the aesthetic realm, the work yielded is required to neither have a level of use nor utility.

Scientists are primarily dependent upon analytical thinking in order to solve scientific problems that exist outside of themselves. Because the conception of scientific problems are largely in response to observed needs, the execution of a scientist's work demands solutions of sustained performance. Furthermore, because the scientist concerns himself with solutions for highly specific scientific problems, the work yielded must be tested and proven.

If artists and scientists anchor two ends of a figurative spectrum, then designers would occupy the conceptual midpoint between the two, in terms of both disciplinary interest and operation -- Designers are equally dependent upon both creative and analytical thinking, and their thinking oscillates between both as they yield creative solutions for problems framed outside of themselves. Furthermore, because the designer concerns himself with solutions that are conceived in the fulfilment of an articulated need, then the creative work yielded possesses a certain level of use and utility. Like artists, designers use creative thinking to narrow their search for acceptable solutions. Like scientists, designers address problems outside of themselves and are therefore engaged in a form of applied research.

This running description of the differences between artists, designers and scientists is necessarily oversimplified in order to quickly appreciate the major differences between them. And while most artists are unlikely to make key contributions to the knowledge base of science, the history of design provides us with architects who have extended themselves outside of their own disciplinary expertise to make new productive contributions within others. More appropriately, architects have historically played a role as technological innovators. Among them are: 
- Filippo Brunelleschi and his inventive structural solution for the Florence Cathedral dome.

- $\quad$ Frank Lloyd Wright and the structural performance of pre-cast concrete columns in the Johnson Wax building in Racine Wisconsin.

- Norman Foster and the various inventive systems coordinated together in the HongKong Bank headquarters.

- Jean Nouvel and the operable south façade design for the Arab World Institute (IMA) in Paris France.

Of all architects who have also established themselves as technological innovators, then Eero Saarinen is arguably the greatest of these. Throughout Saarinen's distinctive portfolio of modern architecture, we find unprecedented architectural types that not only require new technological solutions, but are conceptually dependent upon the success of these innovations. For instance, the Jefferson Memorial (Gateway Arch) in St Louis, neverminding its structural design, required an inventive design for a new vertical conveyance system that would respond to a varying arc of incline as well as accommodate a high volume of visiting patrons. The General Motors Technical Center in Warren Michigan was a design vehicle for inventing several new architectural products that would eventually become industry-standard. These include the use of neoprene gaskets for sealing glass units in metal frames, the creation of insulated metal panels with porcelain enamel finish, and the glazed brick [1]. Dulles Airport outside of Washington DC required an inventive solution to transport airline passengers to larger jetliners that were necessarily parked away from the terminal proper due to the feared effects of jetwash on architectural surfaces. (This was later circumvented with tug taxis which are now industry-standard in airports worldwide. Nonetheless, some of Dulles' mobile lounges remain in operation.) When these examples are considered together, it becomes clear the Saarinen office embraced a very high-risk, high-reward design strategy that we rarely find in the United States today, likely due to legal liability, the prevalence of reproductive thinking at our discipline's centre, and a general lack of personal bravery.

If the architectural discipline is to reclaim its influence and command of the built environment, then they must conceive of research-led and performancebased solutions that address architectural issues beyond a self-serving interest in photogenic aesthetics and the market-serving provision of habitable space. For it is out of this desire for a performative architecture that our university-based design / research team has identified and focused on a problem that involves renewable energy production, electrical transmission, and urban land use policy. We believe a Renewable Energy Infrastructure (REI) will solve this problem.

\section{Premise: five axiomatic truths}

At this preliminary point, our REI problem is informed by both a variety of observable phenomena in the larger world and also a variety of internal expectations for conceptual and developmental strategies in forthcoming designs. While we observe an increasing demonstrated need for alternative modes of 
electrical production and transmission, our position within the disciplinary boundary of Architecture does not afford convenient opportunities for credible investigations into Infrastructure design. Instead, they have to be claimed, and in so doing, challenge the historical role that engineers have played in the conception and execution of new infrastructure types.

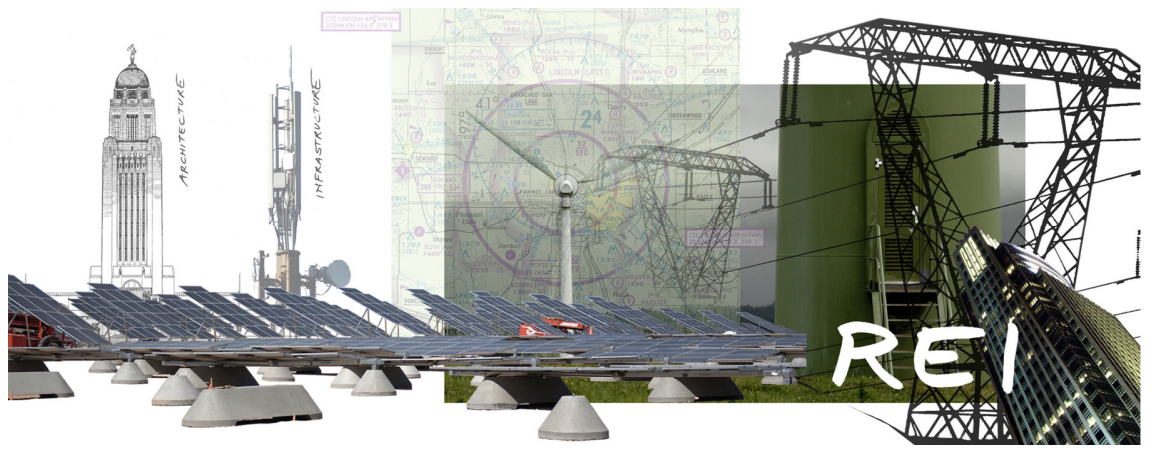

Figure 1: A composite ideogram identifying issues related to a REI: Renewable Energy Infrastructure.

Our design-led research REI effort seeks to gain credibility in the ultimate postulation of technically-plausible design solutions using existing and emerging renewable energy technologies that can be found on the market in the year 2010 . In the face of very real demonstrated needs, our forthcoming solutions seek to address and fulfil these needs with viable solutions that are both "design ready" and "shovel ready." We would be disappointed if the only venue for disseminating our resulting REI solutions were alongside these speculative designs. To this end, the REI research / design investigation is premised upon five axiomatic truths.

Axiomatic Truth Number One: "Due to the Greenhouse Effect caused by carbon dioxide emissions from fossil fuels, there is a need to invent and deploy more environmentally-responsible modes of electrical production to meet an increased demand by modern society." If you are not already privy to the data that supports this statement, then you are likely not attending a conference titled ECO-Architecture, and you are also not likely to be reading a paper containing the words "Renewable" and "Energy" in its title.

Axiomatic Truth Number Two: "On a per square mile basis, urban areas have significantly more demand for electrical energy than rural areas."

Axiomatic Truth Number Three: "Modes of renewable energy production are typically located in rural areas due largely to social and political forces. Furthermore, these modes are technologically proprietary and so far only capitalize on one exclusive resource."

Axiomatic Truth Number Four: "Due to the physical properties of our current electrical grid system, there are measurable falloff rates of megawatts (approximately 10 to $15 \%$ ) from their originating power source (in rural areas) along the transfer length to the end user (in urban areas)." Current renewable 
energy technologies of industrial scale, such as wind farms and solar arrays, are typically located in rural areas and therefore the efficiency with which they serve energy-thirsty urban areas is compromised. For every single megawatt lost during transmission, .4 is due to "evaporation" along transmission lines and .6 occurs during step-downs at sub-stations and transformers.

Axiomatic Truth Number Five: Transfer efficiency can be increased by collapsing the physical distance between the original renewable energy powersource (in an urban area) to the end user (in an urban area).

Considering these axiomatic truths, is it possible then to design a freestanding infrastructure for an urban environment that holistically considers renewable energy-producing agents such as wind, solar, geotechnical, and if applicable, hydrological resources into one holistically-designed entity?

\section{The REI as a new infrastructure typology}

Our team wanted to first pre-emptively understand the historic emergence of new infrastructure types and their level of acceptance achieved with the population that it serves. Society has psychologically accepted the presence of large-scale infrastructure types due to their performance - it is implicitly understood that the level of performative benefit of infrastructure shall exceed any adverse impact that said infrastructure has in the collective viewshed. While both urban and suburban dwellers alike have visual access to multiple infrastructure types in a given day, these populations have developed a psychological comfort with the presence of infrastructure through familiarity, and their physical presence does not adversely impact us since it is already incorporated into one's realm of experience.

Specifically, we investigated the emergence of water towers, cell phone towers, and grain elevators. Surprisingly, we are finding very little opposition during the proliferation of water towers, but only praise - The public at large seemed to understand the performative benefits of this emerging type and were immediate beneficiaries of their widespread proliferation and successful operation. However, with the emergence of cell phone towers in the late 1980s, there was widespread vocal opposition to this new infrastructure type and its impact on viewsheds. Unlike water towers which were immediately understood as a public amenity, cell phone service was an endeavour of private commerce and did not serve the needs of the general public. Furthermore, the price point for early cell phone service and equipment was relatively high for most potential end-users and their budgets, and this worked against any rapid psychological assimilation of cell phone towers in our cultural consciousness. However, as cellular service costs decreased, an increasingly larger portion of society became users of this private service, and we have since conditionally accepted the visual presence of these towers in our viewsheds as long as they continue to provide cellular service and enhanced cellular signal strength. Within the State of Nebraska, the most regionally-appropriate example of psychological adoption stems from sentry-like grain elevators distributed throughout urban, suburban and rural environments in the American Midwest. While their sublime presence 
is startling to visitors from non-agricultural regions, they have been completely psychologically assimilated by the local population and are rarely read as foreground objects. Their performative benefit as objects of infrastructure is understood, and their importance to the region as local economic engines is also understood. Despite their sentry-like stature, these grain elevators dot our viewsheds, but with little to no public opposition.

When forecasting upon the physical scale a REI would require to generate electrical energy at industrial levels, we presumed that a REI would be of such a physical scale and construction type that it could read as a mid-rise or high-rise building. In light of this, it becomes clear that a REI needs to first establish credibility through its quantified performance in order to then effectively challenge restrictive urban zoning policies, provoke NIMBY attitudes and induce market transformation.

A REI seeks to generate renewable energy megawatts (MW) at an industrial scale through the simultaneous harnessing of wind, solar, and geothermal resources, but within an integrated, holistic, and free-standing facility positioned in an urban environment. A REI is not a retrofit of a pre-existing architectural condition, but rather is conceived as a new infrastructure typology to be owned and operated by an electrical utility for purposes of servicing users in highpopulation areas.

\section{The framing of an unprecedented design problem}

According to the 2008 US Census, the State of Nebraska ranks 38th in population (out of fifty states) with 1,783,432 residents. This ranking places Nebraska in the lowest 25 th percentile of the United States. In contrast to its lower population however, the State of Nebraska ranks very high in access to wind, solar and geothermal resources capable of producing renewable energy. Climatic resource availability has been thoroughly documented by the National Renewable Energy Laboratory (NREL), and on a technical level, we recognize that an optimized REI design would be custom tailored to its specific solar, wind, and geotechnical (and if applicable, hydrological) resources. Therefore, the design of a REI in Tucson AZ would look and operate very differently from one designed for Fargo ND. The specific design parameters for either would include the highest level of specificity for angles of solar incline, direction of solar arc, wind speeds achieved at higher elevations, and overall percentages of wind and solar energy technologies. All of these parameters require review in order to optimize electrical yields produced by the REI. The project deliverables that we are looking to yield shall require working with the State of Nebraska's various public power districts in the design of (3) sitespecific, technically-plausible REI solutions of escalating scale in Columbus NE (population 21,595), Lincoln NE (population 251,624) and Omaha NE (population 438,646). These forthcoming options shall be site-specific to maximize urban site conditions although they already share very similar climatic conditions. 


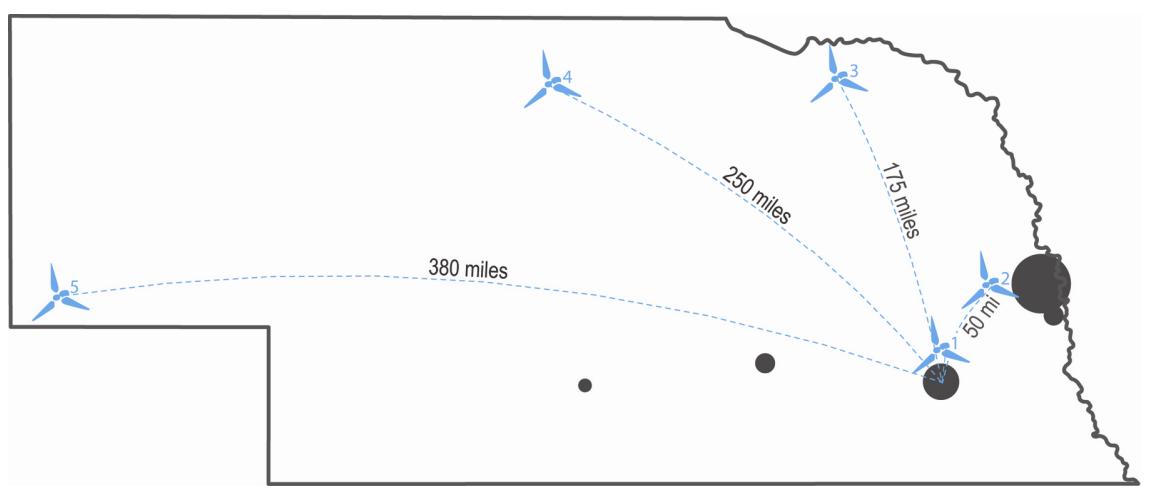

Figure 2: A map of the State of Nebraska locating each of its five operational wind farms, each of the five largest cities, and the linear travel distances between the rurally-located wind farms to those urban areas with the maximum number of end users. If all windgenerated renewable energy MWs were diverted to Lincoln NE, they would travel a total of 906 miles.

In terms of wind, the US Department of Energy ranks the State of Nebraska as 6th in wind energy potential. Despite this strength in climatological circumstances, Nebraska in 2009 surprisingly ranks only 24th in actual wind energy production with a current rate of $153.2 \mathrm{MW}$. In terms of solar, the US Department of Energy ranks the State of Nebraska as 19th in solar energy potential with a Sun Index of .89 , but there are no industrial-scale photovoltaic arrays currently operating.

Of the 153.2 MW of renewable energy produced in the State, $10 \%-15 \%$ of this amount is believed to be lost during transfer due to degradation along transmission lines and processing through transformers. This amount totals 15.3 - 23.0 MW lost over 906 miles of long span transmission lines from five different wind farm locations, all of which are located in rural areas. We believe that we can significantly reduce this amount of loss by collapsing the distance between where renewable energy is produced, and where it is consumed.

There are several constraints when determining an appropriate site for a REI. Due to the highest need for performance, a site should be chosen that eases the distribution of electrical energy generated, but does not compromise its generation potential by positioning itself amongst urban obstacles, such as other buildings. Depending upon their respective size, proportion and solar position relative to the REI, these obstacles could foil the operation of the REI by either creating wind turbulence or shade the REI from valuable solar exposure. Another constraint in play is the economic feasibility of a REI given real estate property values. A REI developed on a site with commercial value would likely not be a cost-effective solution when compared to other energy generation facility types. Furthermore, this private land would then require re-zoning for industrial use, and would likely be denied by any municipality with reasonable 


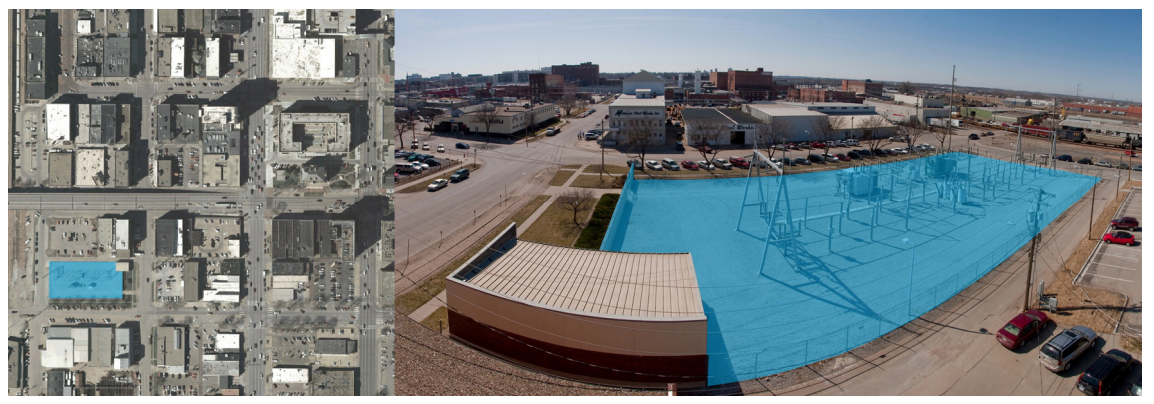

Figure 3: Location map of Lincoln NE showing the selected REI site at $8^{\text {th }}$ Street and N Street. This site is owned by the City of Lincoln and leased to the Lincoln Electric System for an electrical transformer site.

concerns about open high-voltage lines in an otherwise vibrant downtown. The best sites for a REI are likely to be on the periphery of our downtown areas.

In an optimum scenario, if all other site requirements allow, REIs would be ideally positioned on sites already operated by electrical utilities and with existing transformer equipment. If the presence of this new REI construction would not itself precipitate a significant upgrade or overhaul of pre-existing transformer equipment, then the REI could feasibly occupy the airspace of this site, thereby tapping into an existing network without increasing project costs and yet improving urban land use policy. Although a REI would have a physical presence similar to that of a building, the REI would not have appropriated square footage per se, and would only be occupied by utility persons for inspection, service and repair.

The site selected for our REI v1.0 study is located in downtown Lincoln NE, immediately south of the historic Haymarket District. The site is owned by the City of Lincoln, but is leased to the Lincoln Electric System utility as an electrical transformer site. Our REI site is the airspace above this existing electrical infrastructure and in so doing, affords us the ability to tap into a previously existing electrical distribution network without increasing project costs. Furthermore, it allows a REI to occupy an urban context without acquiring privately-held land and / or demolishing existing real property.

Due to the danger presented by large-scale mechanical components in movement, we recognize the very real life-safety concerns that are associated with a REI in an urban environment. Whereas photovoltaic panels present a very low hazard level of operation, the failure of large horizontal-axis wind turbines is oftentimes both spectacular and irreparable. In the event that a bearing generates too much heat during rotation, the turbine house may catch fire due to overheating by friction. However, since these turbine types are typically located in rural areas, the horizontal-axis turbines are often allowed to burn out in place. Firefighting teams will set up a secure perimeter around the problem turbine, and protect against falling debris, including the turbine itself. Proper maintenance can prevent such fatal problems for wind turbines, but high wind speeds present 
another set of life-safety issues. In the event that wind speeds push blade revolutions beyond their recommended operating limits, there is a safety braking mechanism that shuts down the rotation of the turbine blades. However, these braking systems can sometimes fail. Under increasing wind speeds, turbine blades that continue to spin beyond their operational specifications can put considerable structural stress upon its respective support mast as well as the profile of the blades themselves. Under such stress, the structural profile of the mast can deflect enough to topple the spinning turbine to the ground or the blades themselves can deflect enough that they collide with the mast as they are spinning. In either case, the power exerted and quickness demonstrated in such destructive acts are marginalized in rural settings, but would certainly cause considerable collateral damage to both life and property if similar technological failure occurred in an urban setting.

\section{Preliminary designs}

With the design problem reasonably formed, we then sought out any design precedents that may have stemmed from a similar set of site, program and user circumstances. We were pleased to find the smaller-scale Oasis by Laurie Chetwood and the larger-scale Solar Net winning entry for the 2001 US Department of Energy Sunwall Design Competition [2]. Upon familiarizing ourselves with the design intent behind this latter Solomon Cordwell Buenz / Arup proposal, we appreciated the innovative form of the sloped concave photovoltaic wall which allowed itself to be intelligently-shaped according to the winter and summer solstice positions. Furthermore, as with all of the competition entries, we appreciated its willingness to engage non-rural, densely populated sites for generating renewable energy.

We believe the innovative value of our REI proposal lies in the bringing together of multiple renewable energy technologies on a single urban site in a deliberate, hybridized, and technologically unbiased way. While the REI is looking to establish credibility through generating quantifiable electrical yields at industrial scales, it also addresses other multiple aspects of our nation's energy problem (the political, economic, carbon emissions, and technical) while having some collateral benefit to non-energy areas (in commerce, design, and engineering).
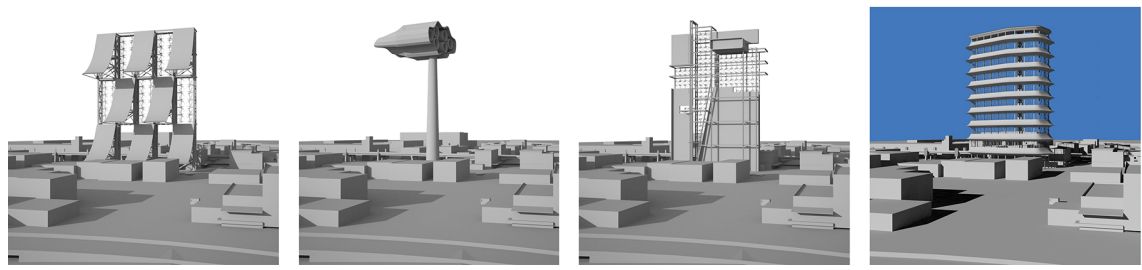

Figure 4: Preliminary designs for a REI sited in Lincoln NE. The design chosen for further development is shown at the far right. 
Our preliminary designs were the result of a three day charette exercise. Our design strategy was to first use creative thinking to generate multiple options for consideration, and only then use analytical thinking to identify those traits and qualities that we wanted to ultimately carry forward into the developed REI design.

The first scheme sought to feature sloped concave profiles to optimize yearly solar angles for the $41^{\text {st }}$ latitude. However, these profiles were also arranged to deflect prevailing southern winds upwards to double the air velocity moving through the vertical axis turbines located immediately above. However, due to the staggered patterning of the solution, we recognized that shadows cast upon the photovoltaics below were self-defeating. In this scheme, overall power generation would likely be; Wind $=34 \%$, Solar $=33 \%$, Geothermal $=33 \%$.

The second scheme explores the possibility of (6) small diameter horizontal axis turbines covered with a photovoltaic fuselage skin. Supported by a single mast, the face of the turbine blades would always rotate to front applicable winds, and the photovoltaic fuselage would further assist the proper wind orientation with fin profiles. In order to best capture wind resources, REI schemes incorporating wind technology would need to occupy the highest elevations that municipal zoning regulation will allow. In this scheme, overall power generation would likely be; Wind $=50 \%$, Solar $=25 \%$, Geothermal $=$ $25 \%$.

Whereas the first and second schemes sought an aesthetic informed by scientific determinism, the third scheme explored a composition of vertical axis turbines and photovoltaic surfaces for its own aesthetic sake. Furthermore, we brainstormed on possible architectural programs that may also benefit from being incorporated into this scheme. We would soon conclude that whatever interest was gained in composition, it lost credibility in energy performance. This scheme was immediately rejected since it was not congruent our criteria for beneficial infrastructure design - Infrastructure design should not sacrifice physical performance for the sake of compositional aesthetics. In this scheme, overall power generation would likely be; Wind $=25 \%$, Solar $=25 \%$, Geothermal $=50 \%$.

The fourth and final scheme is informed by attributes of each of the first three schemes. It is not self-conscious about its own aesthetic, but rather seeks maximum electrical production through wind, solar and geothermal resources. Scheme "D" has been selected for further investigation.

\section{REI v1.0: Lincoln NE}

We are finding our preliminary REI design from March 2009 to have the technological potential of generating $124 \mathrm{MW}$ of renewable energy.

This scheme for Lincoln NE assumes a maximum allowable REI zoning height at 400'-0" which is equal in height to the Nebraska State Capitol building by Bertram Goodhue (1932). To maximize this likely height restriction, this REI provides (8) stacked tiers of integrated wind / solar modules each set every 40'0 " in infrastructure height. 

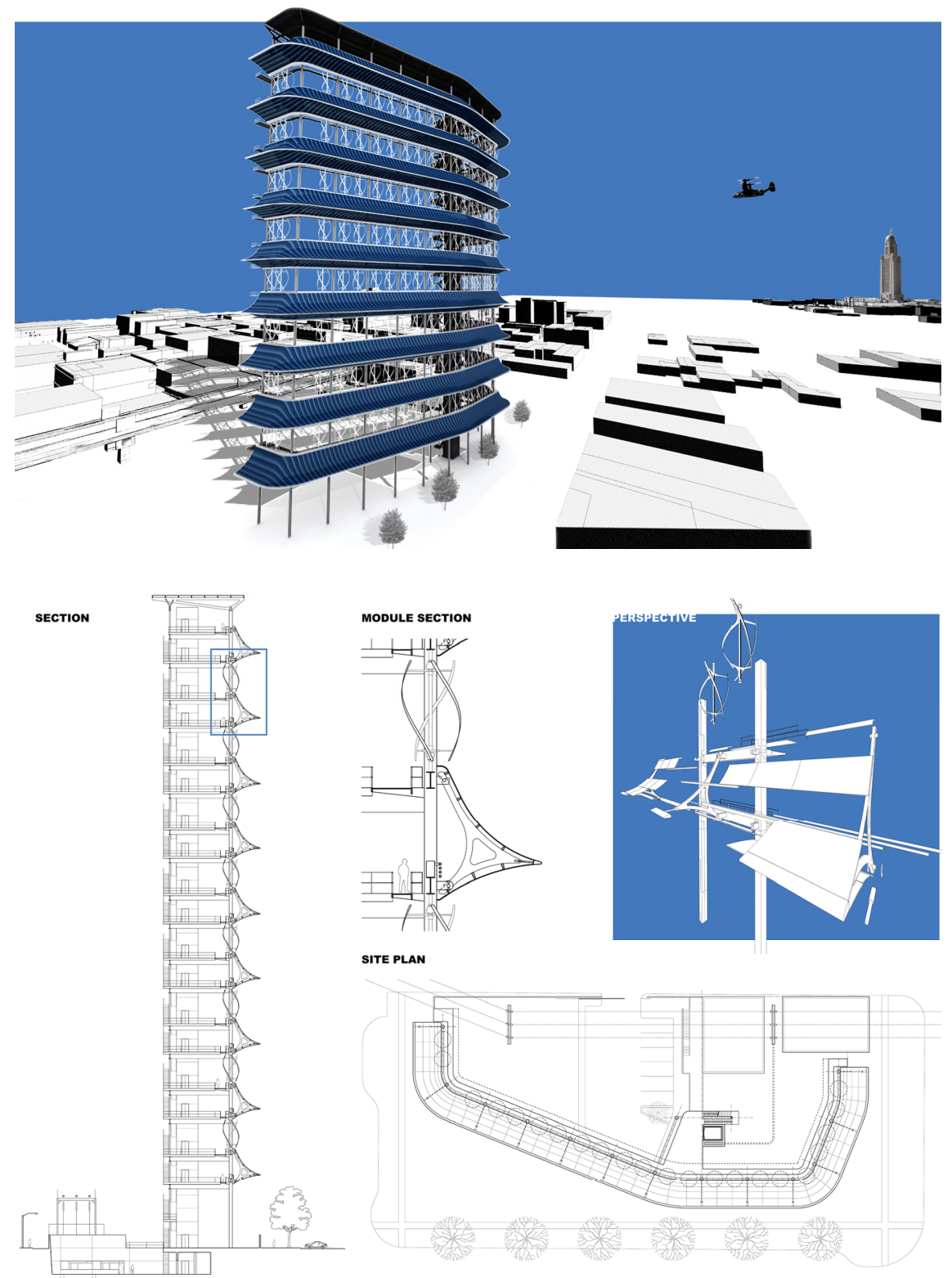

SITE PLAN

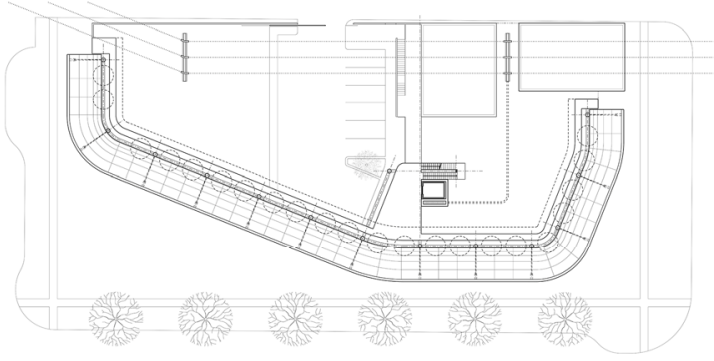

Figure 5: Design materials used to represent our REI v1.0 include perspectives, site plan, transverse section, enlarged component section, and exploded view of vertical-axis turbines, photovoltaic panels, and structural system. 
Energy Production - Wind: Equipped with quietRevolution qr5 v1.3 Vertical Axis Wind Turbines. (22) turbines per floor with (8) floors $=176$ qr5 turbines. 1 qr5 turbine $=2.74 \mathrm{~kW} @ 12 \mathrm{~m} / \mathrm{s}$. Seasonal wind data for Lincoln NE suggests that these turbines can likely generate: Jan thru Mar $=563 \mathrm{~kW}$, Apr thru Jun $=1.056 \mathrm{MW}$, Jul thru Sept $=1.144 \mathrm{MW}$, Oct thru Dec $=528 \mathrm{~kW}$.

Energy Production - Solar: Equipped with custom-shaped Schott ASE-250DGF photovoltaic panels. 187,220 sq. ft. of PV panel per floor with (9) floors = $1,684,980$ sq. ft. PV panel area. 1 sq. ft. of Schott PV produces $.012 \mathrm{~kW} x$ $1,684,980$ sq. ft. $=20.22 \mathrm{MW}$ generated.

Energy Production - Geothermal: The NREL has published that the State of Nebraska has access to internal core temperatures of 100 to 200 degrees Celsius.

This REI design assumes its construction would be phased as a scalable system where smaller portions of a REI can become operational prior to a complete build-out of the overall design. This economic model for implementation would benefit from streams of funding over time and would only then yield the highest amounts of MW once completed. It is our expectation that a REI would have upgradeable, hot-swappable technological components to both maximize life expectancy and design against expiration due to technological obsolescence. The cast aluminium frames can be attached and detached with relative ease in order to maximize access to the REI's structural frame, its electrical conduits, and for upgrading the components on the frames themselves. Furthermore, its hybridized technology strategy effectively diverges from the current trend of proprietary system design by companies that exclude other renewable energy types not in their business model / expertise. By combining vertical axis wind turbines and photovoltaic arrays on the same site, we harness multiple climatic conditions simultaneously.

Through the agency of a REI in our urban fabric, we improve the efficiencies of existing electrical technologies, improve urban land use policy, and provide an ecologically-responsible alternative that can dovetail with, or ultimately succeed, prevailing methods of electrical production at industrial scales. More appropriately, as new REIs of industrial capability are constructed, existing greenhouse gas emitting modes of electrical production (such as coal-fired electrical plants) can be decommissioned. This suggests that REIs could be impact players in future energy policy where carbon-emitting emissions can be significantly reduced without having to adversely impact electrical consumption.

\section{Expected outcomes and estimated impact}

The greatest impact of this REI effort shall be the delivery of a plausible, costeffective option for reducing greenhouse gas emissions from Nebraska's public power districts. Because a REI conceptually emerges from the intersection of energy production, global warming, and urban living, it suggests that energy solutions can originate outside of traditional disciplinary boundaries and speaks to the validity of cross-disciplinary, design-led research.

This project is well-positioned to address attributes of our nation's energy problem such as our demonstrated dependency upon importing energy from 
foreign nations and alleviate some of the political and economic pressure associated with a dependency upon this supply line. Without the natural resources to satisfy our own national demand, embracing renewable energy would help us transform our energy market from its current fossil-based forms to domestic wind, solar and geothermal resources that can already be found in abundance stateside.

The execution of a REI would be transformational in its ability to combine, in a deliberate and intentional way, multiple renewable energy technologies in the same physical location and without proprietary technological exclusion. This would effectively diverge from the current trend of proprietary system design by companies that exclude other renewable energy types due to the specificity of their business model / expertise. A REI incorporates renewable energy technologies because it looks to establish credibility through generating quantifiable electrical yields at industrial scales, and does not concern itself those aesthetic issues determined by critics-at-large.

The pursuit of a REI would be a friendly counterpoint to other research efforts in "Smart Grid" transmission technologies by simply collapsing the distance between where electrical energy is produced and where it is consumed. This reduced travel distance for MW will translate into a sharply reduced amount of renewable energy MWs lost.

\section{Acknowledgements}

This scope of research / design work has been executed by a team within the College of Architecture at the University of Nebraska - Lincoln. Team members include Justin Brouillette, Chris Ford, Krissy Harbert, Ryan Henrickson and Jon Miller. This project was originally funded by the 2008-2010 Steward Professorship in Sustainable Design award and has since been awarded additional funding with a 2009 AIA Upjohn Research Initiative grant and a 2009 energy research grant from the Nebraska Center for Energy Sciences Research. These funds will be used to develop the REI design with external partners who are disciplinary experts in their respective fields. These external partners include Mr. Thomas J. Davlin, Manager, Projects Engineering for Lincoln Electric System (LES), Lincoln NE; Mr. John R Larson, P.E., Manager of the Renewable Power Program, HDR Engineering, Minneapolis MN; and Mr. Frank L. Thompson, Manager for Renewable Energy Development, Nebraska Public Power District (NPPD), Columbus NE.

In October 2009, this preliminary REI design received a 2009 "Monster of Design" award from the AIA Kansas City Young Architects Forum.

\section{References}

[1] Serraino, Pierluigi. Saarinen, Taschen: Köln, pp. 35, 2005.

[2] National Renewable Energy Laboratory. Sunwall Design Competition; United States Department of Energy, National Solar Design Competition, Publication Number DOE/GO-102001-1339, NREL: Golden CO, 2001. 